\title{
RNAi Mediated Silencing of Gene Encoding 1-Deoxy-D-Xylulose-5-Phosphate Reductoisomerase (DXR) in Centella asiatica
}

\author{
Richa Sharma, Ratna Kalita, Basanta Kr. Borah, Mahendra K. Modi, Priyabrata Sen* \\ Department of Agricultural Biotechnology, Assam Agricultural University, Jorhat, India \\ Email: *pbsen14@gmail.com
}

How to cite this paper: Sharma, R., Kalita, R., Borah Kr., B., Modi, M.K and Sen,P. (2020) RNAi Mediated Silencing of Gene Encoding 1-Deoxy-D-Xylulose-5-Phosphate Reductoisomerase (DXR) in Centella asiatica. American Journal of Plant Sciences, 11, 1723-1738.

https://doi.org/10.4236/ajps.2020.1111124

Received: September 11, 2020

Accepted: November 20, 2020

Published: November 23, 2020

Copyright $\odot 2020$ by author(s) and Scientific Research Publishing Inc. This work is licensed under the Creative Commons Attribution International License (CC BY 4.0).

http://creativecommons.org/licenses/by/4.0/

(c) (i) Open Access

\begin{abstract}
Centella asiatica (L.) is one of the most valuable medicinal plants since prehistoric times. The pharmaceutical importance of this herb is due to the accumulation of large quantities of pentacyclic triterpenoid saponins, collectively known as centelloids synthesized by the isoprenoid biosynthesis pathway. Biosynthesis of triterpenoid in the plants proceeds via either of the two pathways, viz. Mevalonate (MVA) pathway (in the cytosol) or 2-C-methyl-D-erythritol 4-phosphate (MEP) pathway (in plastid). In Centella, the pathway leading to the accumulation of triterpenoid is still not known or elucidated. Thus, to know whether the MVA or MEP pathway or a cross-talk between the pathway leads to the biosynthesis of triterpenoid, silencing the key regulatory gene using RNAi tool, of each of the pathway and then analyze a metabolite is an efficient approach. The key regulatory enzyme of the MVA pathway i.e. 3-Hydroxy-3-methylglutaryl-coenzyme A reductase (HMGR) has already been successfully silenced using RNAi tool [1]. In the present study, the 1-deoxy-D-xylulose-5-phosphate reductoisomerase ( $D X R)$ a key regulatory enzyme in MEP pathway is silenced. The RNAi- $D X R$ construct in pHANNIBAL vector was cloned into a binary vector pART27 and subsequently transformed into Agrobacterium strain AGL1. The transient analysis of the RNAi-CaDXR using semi-quantitative RT-PCR confirmed the silencing of the endogenous DXR gene in Nicotiana and further confirmed in Centella asiatica. The present study is the first step aimed to delineate the MEP pathway using RNAi silencing approach to elucidate its role in the accumulation of triterpenoid in this important medicinal plant.
\end{abstract}

\section{Keywords}

Centella, DXR, RNAi, Gene Knockdown, Secondary Metabolite, Agro Infiltration 


\section{Introduction}

Centella asiatica (L.) Urban is a herbaceous medicinal plant from Apiaceae family native to Southeast Asian countries such as India, Sri Lanka, China, Indonesia, and Malaysia as well as South Africa and Madagascar [2]. Available literature reveals that this herb has been used since time immemorial in Ayurvedic and Chinese traditional medicines [3]. Moreover, Centella is also listed as a drug in the Indian Herbal Pharmacopoeia, the German Homeopathic Pharmacopoeia (GHP), the European Pharmacopoeia, and the Pharmacopoeia of the People's Republic of China [4] [5] [6] [7]. However, due to continuous cultivation and exploitation, the wild stock of this plant has been markedly depleted due to insufficient replenishment so this herb is listed as threatened plant species by the International Union for Conservation of Nature and Natural Resources (IUCN), and also marked as an endangered species [8] [9] [10]. The medicinal importance of this herb is due to the accumulation of large quantities of pentacyclic triterpenoids saponins, collectively known as centelloids [6] which are produced via. isoprenoid pathway [11]. Biosynthesis of triterpenoid in most of the plants proceeds via either of the two pathways, viz. Mevalonate (MVA) pathway (in the cytosol) or 2-C-methyl-D erythritol 4-phosphate (MEP) pathway (in plastid). In Centella, the pathway leading to the accumulation of triterpenoid is still not known so many promising tools to up-regulate the key components that couldn't be applied to the crop. Among many, RNAi an efficient tool to knock down a gene [12] can be definitely applied to suppress the key regulatory gene in both MVA and MEP pathway and thereby analyzing the accumulation of metabolite which shall provide us with knowledge of the pathway which is responsible for the synthesis of the key compound. The key regulatory enzyme of the MVA pathway i.e. 3-Hydroxy-3-methylglutaryl-coenzyme A reductase (HMGR) has already been successfully silenced using RNAi tool [1]. In the present study, 1-deoxy-d-xylulose 5-phosphate reductoisomerase (DXR) (EC1.1.1.267), the key enzyme that regulates MEP pathway [13] [14] is being silenced. Silencing the key regulatory enzyme of both the pathway and analyzing the metabolite shall shed light on the knowledge of the pathway which leads to the synthesis of key metabolite. The complete gene sequence of $D X R$ from Centella plant has already been submitted in NCBI (JQ965955). We have already completed in silico characterization and differential expression analysis of $D X R$ gene. The study revealed that it contained a 1425 bp ORF encoding a peptide of 474 amino acids. Semi-quantitative RT PCR results revealed that DXR is differentially expressed in various tissues with the highest expression in node followed by leaf, stem and root tissue. The present study is the first step aimed at knock-down $D X R$, a key regulatory enzyme of the MEP pathway and further confirmation through transient analysis.

\section{Materials and Methods}

Centella asiatica plants were collected from botanical garden of Assam Agricul- 
tural University (AAU), Jorhat, Assam, India and grown in pots using recommended agronomic practices. Centella plants were grown in the moist, sandy loam soil and moist humid weather of Assam is very suitable for the growth of this medicinal perennial plant. The Pots containing Centella plants were placed in the greenhouse where the temperature was maintained at $30^{\circ} \mathrm{C} \pm 2^{\circ} \mathrm{C}$ and watered regularly. The tender leaves $(0.1 \mathrm{gm})$ were collected from Centella plants and pulverized in luquid nitrogen and the total RNA was isolated using TRizol reagent (Invitrogen life technologies). Total RNA integrity was assessed by electrophoresis in $0.8 \%$ agarose gel using tris-borate EDTA (TBE) buffer at $5 \mathrm{~V} / \mathrm{cm}$ for $3 \mathrm{~h}$. RNA yield and quality was determined using Nano Drop spectrophotometer (NanoDrop1000, Thermo-scientific) by measuring absorbance at $260 \mathrm{~nm}$ $\& 230 \mathrm{~nm}$.

\subsection{Designing of CaDXR-RNAi Primers and Amplification of Sense and Antisense Strands}

In the present study, pHANNIBAL hpRNAi vector was used for cloning sense and anti-sense strands specific to DXR gene. Centella DXR ((GenBank accession number: JQ965955) gene sequence was retrieved from NCBI and primers were designed using GENE RUNNER software (http://www.generunner.net/) to amplify $273 \mathrm{nts}$ of both sense and anti-sense strands specific to $D X R$. The forward and reverse primer for amplification of the sense strand was designed by adding 5 ' XhoI and EcoRI restriction enzyme site. Similarly, the forward and reverse primer for amplification of the antisense strand was designed by adding the 5 ' flanking sequence of HindIII and BamHI restriction site (Table 1). The Prime Script First Strand cDNA Synthesis Kit (Takara, Japan) was used to synthesize the first strand cDNA from the total RNA $(2 \mu \mathrm{g} / \mathrm{ul})$. Using $1^{\text {st }} \mathrm{cDNA}$ as a template and gene-specific primers (Bioserve, India) the target $D X R$ gene was amplified. The PCR was performed in $20 \mathrm{ul}$ mixture containing $1^{\text {st }}$ strand $\mathrm{CDNA}$ as template 1X Taq polymerase buffer (Thermo Scientific, US), 1U Taq polymerase (Thermo Scientific, US), $10 \mathrm{pm}$ both forward and reverse primers (Bioserve, India) and $5 \mathrm{mmol}$ dNTP mixture (Thermo Scientific, US) were subjected to PCR in Gene Amp Thermo Cycler (Applied Biosystems) and programmed with initial denaturation at $94^{\circ} \mathrm{C}$ for $3 \mathrm{~min}$ followed by 30 cycles of $94^{\circ} \mathrm{C}$ for $30 \mathrm{sec}, 55^{\circ} \mathrm{C}$ for $30 \mathrm{sec}, 72^{\circ} \mathrm{C}$ for $1.30 \mathrm{sec}$ and a final extension of $72^{\circ} \mathrm{C}$ for $1.30 \mathrm{sec}$.

Table 1. List of $C a D X R$ RNAi primer pair.

\begin{tabular}{|c|c|c|c|}
\hline Primers & $\begin{array}{l}\text { Forward Sequence }\left(5^{\prime}-3^{\prime}\right) \\
\text { (FDXRNAi) }\end{array}$ & $\begin{array}{l}\text { Reverse Sequence }\left(5^{\prime}-3^{\prime}\right) \\
\text { (RDXRNAi) }\end{array}$ & $\begin{array}{l}\text { Annealing } \\
\text { Temperature }\end{array}$ \\
\hline $\begin{array}{l}\text { Sense } \\
\text { strand }\end{array}$ & $\begin{array}{c}\text { GCCTCGAGAAGTTATTGAAG } \\
\text { CTCACTATCT }(X h o 1)\end{array}$ & $\begin{array}{c}\text { ACGAATTCGCATAGAGGGT } \\
\text { ACTTCACATT (EcoRI) }\end{array}$ & $\begin{array}{l}55^{\circ} \mathrm{C} \text { for } 30 \\
\text { seconds }\end{array}$ \\
\hline $\begin{array}{l}\text { Anti-sense } \\
\text { strand }\end{array}$ & $\begin{array}{c}\text { ACGGATCCAAGTTATTGAAG } \\
\text { CTCACTATCT (BamH1) }\end{array}$ & $\begin{array}{l}\text { TTAAGCTTGCATAGAAGGGT } \\
\text { ACTTCACATT (HindIII) }\end{array}$ & $\begin{array}{l}55^{\circ} \mathrm{C} \text { for } 30 \\
\text { seconds }\end{array}$ \\
\hline
\end{tabular}




\subsection{Restriction Digestion and Purification of PCR Product (Sense and Antisense Insert)}

PCR products were subjected to double digestion with restriction enzymes Xhol and EcoRI (Thermo scientific) $10 \mathrm{U} / \mathrm{ul}$ for digestion of sense fragment and HindIII and BamHI (Thermo scientific) $10 \mathrm{U} / \mathrm{ul}$ concentration for antisense fragment. The reaction was incubated at $37^{\circ} \mathrm{C}$ for 1.30 hours. Digested products were checked in $1 \%$ Agarose gel and size was confirmed by 100 bp ladder (step up, Thermo scientific). Sense and antisense products of size $273 \mathrm{bp}$ were purified by Gen Elute Gel Extraction Kit (Sigma, USA) according to manufactures instructions.

\subsection{Cloning of Sense and Anti-Sense Strands into pHANNIBAL Vector}

The PCR amplified and purified products were then directionally cloned into pHANNIBAL-RNAi vector, in which T-DNA includes a selectable marker gene and a strong promoter (CaMV35S) upstream of a pair of multiple cloning sites flanking an intron. This structure allows one to clone sense and antisense copies of a gene of interest, separated by the intron. Ligation reactions were carried out to incorporate sense and antisense strand into multiple cloning sites of the RNAi vector pHANNIBAL. The ligation mixture contained $\sim 200 \mathrm{ng}$ vector, $\sim 600 \mathrm{ng}$ insert, 10× Ligase buffer, 1 unit of T4 DNA Ligase; sterile distilled water was added finally to adjust the final volume to $10 \mu$ l. Ligation reactions for cohesive ends were incubated at $16^{\circ} \mathrm{C}$ overnight. The ligation mixture was transformed into $E$. coli $\mathrm{DH} 5 \alpha$ cells by using the heat shock method. And transformants were selected on LB plates containing ampicillin.

\subsection{Confirmation of Recombinant Clones by Colony PCR and Restriction Digestion}

The colony PCR was carried out to observe for the presence of the recombinant plasmids in transformed bacterial colonies wherein amplification of the inserted DNA was done using specific primers. A single isolated colony was picked up with a sterile toothpick and transferred to a micro centrifuge tube containing 50 $\mu \mathrm{l}$ double distilled water the individual transformants were lysed in $\mathrm{H}_{2} \mathrm{O}$ with short heating $\left(100^{\circ} \mathrm{C}\right)$ step that causes the release of the plasmid DNA from the cell, so it can serve as the template for the amplification reaction. Primers designed (Table 1) to specifically target the sense insert DNA was used to determine if the construct contains the DNA fragment of interest. The PCR profile used was same as mentioned above.

Further confirmation of the colony PCR positive clones was done by doubledigestion of the recombinant pHANNIBAL vector with Recombinant pHANNIBAL vector were double-digested with different combinations of restriction enzymes (XhoI, EcoRI; BamHI, HindIII) to confirm the size, orientation and location of the inserts and finally digested with NotI restriction enzyme for con- 
firmation of the presence of the RNAi cassettes.

\subsection{Cloning of Recombinant pHANNIBAL Vector in the pART27 Binary Vector}

The pART27 binary vector was first digested with the Not $\mathrm{I}$ restriction enzyme. The RNAi cassette in the pHANNIBAL vector was released by digesting with the same restriction enzyme i.e. Notl. Then the binary vector was treated with calf alkaline phosphatase (CIP) to prevent self-ligation. CaDXR-RNAi construct (Figure 1) was cloned into the Not I site of binary vector pART27 using T4 DNA ligase and transformed into $E$. coli strain DH5 $\alpha$. Insertion of the insert into pART27 binary vector disrupts the expression of the lac $Z \alpha$, thus blue (non-recombinant) and white colonies (Recombinant) were observed upon transformation. The plasmid from the recombinant white colonies was isolated and the size of the insert was determined by digestion of the recombinant plasmid with restriction enzymes (XhoI, EcoRI, and BamHI, HindIII).

\subsection{Transient Expression Analysis of DXR-RNAi Construct in Nicotiana tabacum and Centella asiatica}

Binary vector pART27 with RNAi cassette was electroporated into Agrobacterium strain AGL1 by using Bio-Rad Micro Pulse System. Agrobacterium cells were spread on solid LB medium containing Spectinomycin $(100 \mathrm{mg} / \mathrm{l})$ and rifampicin $(20 \mu \mathrm{g} / \mathrm{ml})$ and incubated at $28^{\circ} \mathrm{C}$ for 3 days. The transient expression analysis of RNAi-DXR in Nicotiana tabacum and Centella (Figure 2) was carried out by the Agro infiltration method as described by [15]. Before infiltration, a small incision was made at the site of infiltration using a sterile toothpick to enhance the efficiency of infiltration. Infiltration was performed with $5 \mathrm{ml}$ syringe by simply pressing the syringe (no needle) on the underside of the leaf and exerts a counter-pressure with the finger on the other side. Successful infiltration is often observed as a spreading "wetting" area in the leaf. The first three leaves counting from the top of 6-week old Nicotiana and Centella plants was used for infiltration of transformed $A$. tumefaciens strains and infiltrated into the underside of the leaves of both the plants to determine the sub cellular location of the protein [16]. After infiltration, the plants were moved back to the growth room and allowed to grow at $21^{\circ} \mathrm{C}, 14 \mathrm{~h}$ light and $10 \mathrm{~h}$ dark to monitor the protein expression after 4, 6 and 8 days post infiltration (dpi).

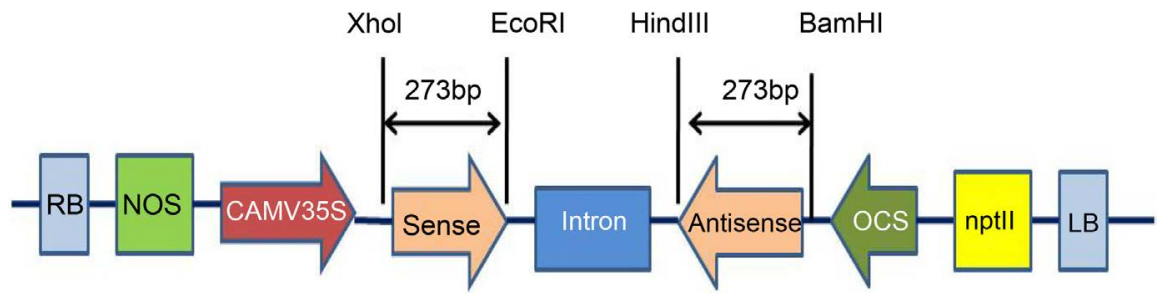

Figure 1. Centella DXR RNAi construct with sense and antisense DXR sequence flanking a $p d k$ intron under the control of CaMV35S promoter and OCS terminator. 


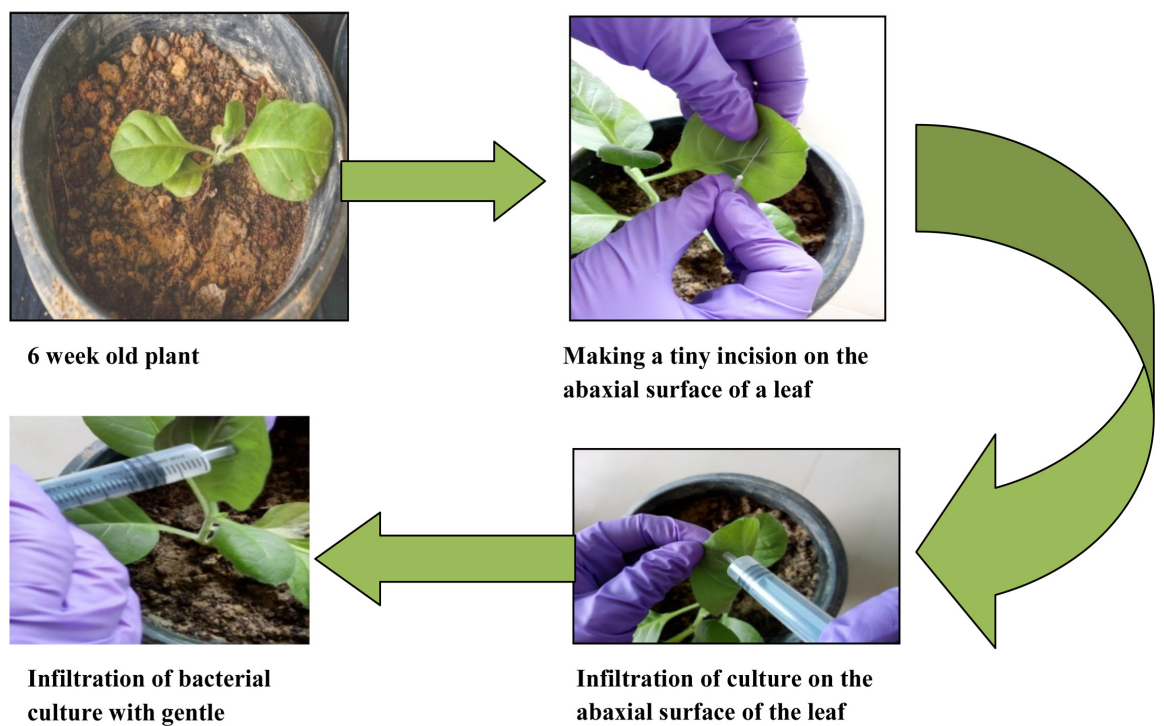

Figure 2. Agro infiltration for transient expression analysis in tobacco \& centella.

\subsection{Expression of $D X R$-RNAi Construct Using Semi-Quantitative RT-PCR}

Total RNA was isolated from control (no agro infiltration) and the agro infiltrated leaves at the interval of 4 days, 6 days and 8 days from both Nicotiana and Centella plants. Semi-quantitative PCR was performed by using one-step reverse transcription polymerase chain reaction (RT-PCR) kit (Qiagen, Germany) with the $D X R$ specific primer and Ubiquitin 10 primer (Forward 5'TGGTCAGTAATCAGCCAGTTTGG3' and Reverse

5'GCACCACAAATACTTGACGAACAG3') was used as loading control. First strand synthesis was carried out at $50^{\circ} \mathrm{C}$ for 30 minutes and second strand synthesis was carried out at an annealing temperature of $55^{\circ} \mathrm{C}$ for 30 seconds and 30 cycles. At the end of the run, the reaction mixture was loaded on $1 \%$ agarose gel and viewed under gel documentation system.

\section{Results and Discussion}

\subsection{Designing of DXR-RNAi Construct}

In many medicinal plants, the metabolic pathway responsible for the accumulation of the key metabolites and its regulation is still in its infancy. And prior knowledge of the pathway which causes accumulation of the secondary metabolite in medicinal plant Centella and their regulation is an important prerequisite before any molecular intervention is done.

In the present study, total RNA was isolated from tender leaves of the Centella plant grown in pots by Trizol reagent. Centella being medicinal plant its tissues are a rich source of secondary metabolites and polyphenols which tends to co-precipitate with the RNA so isolation of good quality RNA from this plant tissues is troublesome [17]. Therefore, along with Trizol reagent $\beta \mathrm{ME}$ and PVP are added to the homogenized buffer. Denaturing agarose gel electrophoresis of 
isolated RNA samples showed a clear, distinct and intact band of $28 \mathrm{~S}$ and $18 \mathrm{~S}$. A260/A280 ratio also clearly indicates good the quality of the isolated RNA and the approximate yield was found to be $3.8 \mu \mathrm{g} / \mu \mathrm{l}$. Thus, the RNA isolated was assured to be of high quality and purity as evidenced by nanodrop reading as well as gel analysis, hence should be amenable to further downstream applications.

The analysis of gene function by systematic mRNA ablation by RNA interference (RNAi) has been a very viable option especially in scenarios where genetic knockout or any other reverse genetics approaches are not available. The application of RNAi technology has been a transforming event in biological research and it has become an essential tool for the functional analysis of genes and to increase the key metabolite by suppressing the expression of the deleterious gene. RNAi silencing mechanism has been studied in various medicinal plants to explain the metabolic pathway responsible for the synthesis of important secondary metabolites. In the medicinal plant, the California poppy RNAi approach was used to block the activity of the berberine bridge enzyme (BBE) which led to the accumulation of (S)-reticuline, which is an important intermediate in the biosynthesis of isoquinoline alkaloid [18]. However, previous efforts to accumulate reticuline in this medicinal plant using the antisense RNA approach were not successful [19] [20]. The first committed step in the synthesis of ginsenosides (triterpenoid saponins) a key pharmaceutical ingredient was catalyzed by the gene encoding oxidosqualene cyclase enzyme in the medicinal plant ginseng [21]. They could provide this evidence by silencing the oxidosqualene cyclase gene through RNAi technology hence they found up to $\sim 85 \%$ reduction in ginsenoside production in roots. A neurotoxin called $\beta$-oxalylaminoalanine-L-alanine (BOAA) [22] is found in a leguminous crop called Lathyrus sativus and on consuming this vegetable people suffered from a paralytic disease called, lathyrism. RNAi technology to silence the gene(s) responsible for the production of BOAA was also reported [23]. Based on these studies in our study also we tried to knock down the key regulatory gene $D X R$ of MEP pathway to understand the regulatory role played by this enzyme in the accumulation of secondary metabolites.

In the present study, the pHANNIBAL RNAi vector was used to directionally clone PCR products of $273 \mathrm{bp}$ (Figure 3 ) from Ca-DXR gene to be easily converted into a highly effective hpRNA silencing construct. The vector pHANNIBAL was designed so that sense and antisense PCR fragments could be inserted in the sense polylinker site (XhoI and EcoRI) and in the antisense (Hin$d$ III and BamHI) polylinker site of the vector respectively. The ligated products were immediately used for the transformation of E. coli DH5 $\alpha$ competent cell via. heat shock method. The size of the inserts (sense and antisense) and ligation was confirmed by restriction digestion of the recombinant PHANNIBAL vector. Restriction digestion with sense restriction enzymes (XhoI and EcoRI) and antisense restriction enzymes (BamHI and HindIII) confirmed the release of $273 \mathrm{bp}$ fragments in $1 \%$ agarose gel (Figure 4). In plants, several approaches have been 


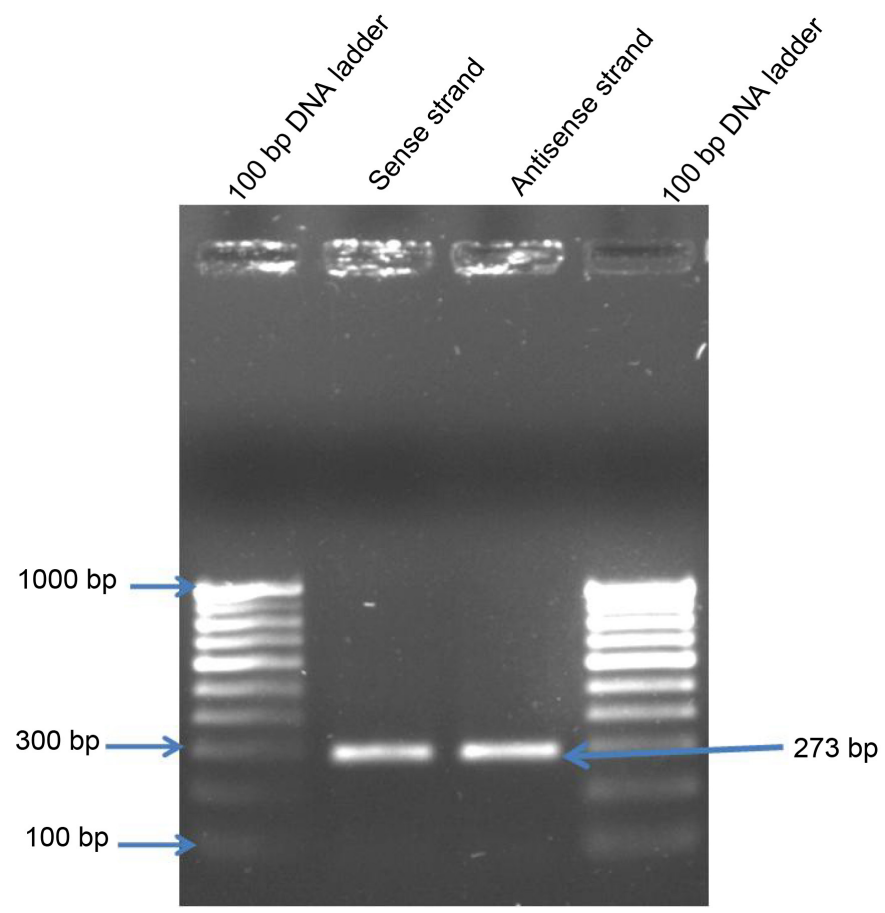

Figure 3. Electrophoretic pattern representing of PCR amplified sense and anti sense strand using DXR specific primers of centella.

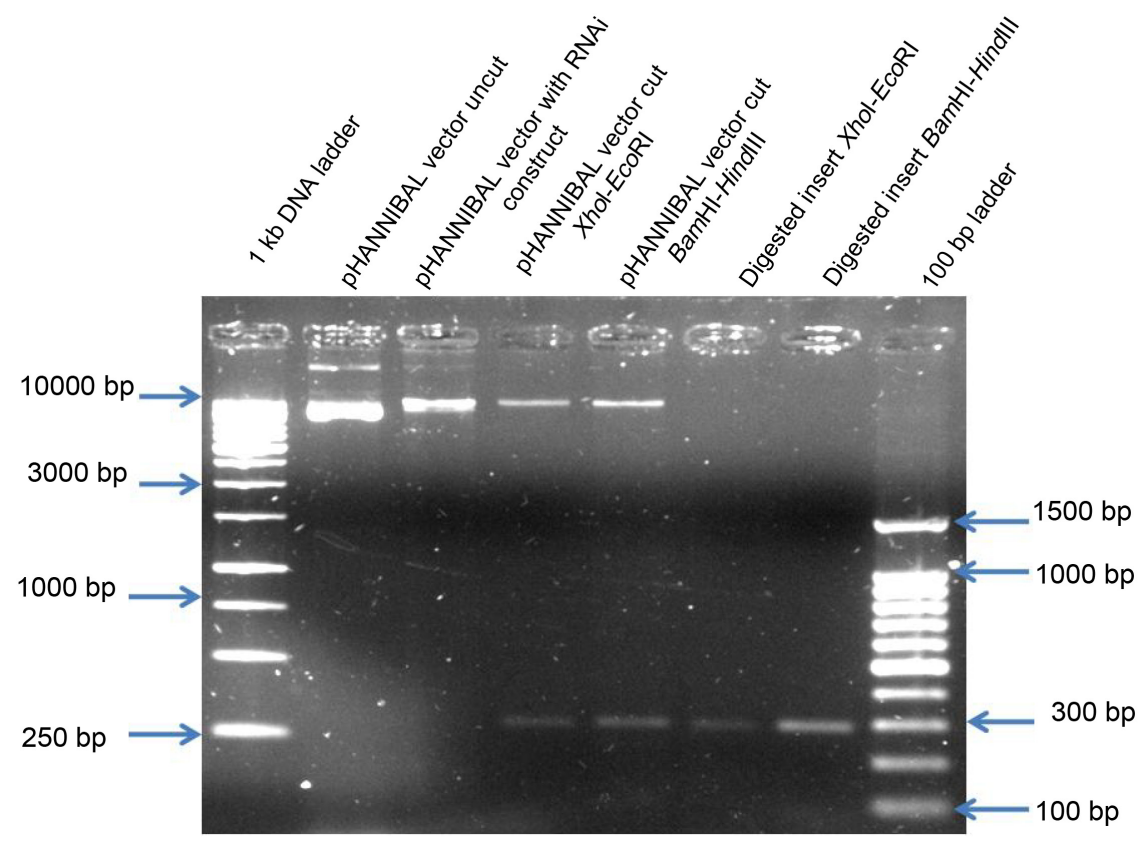

Figure 4. Electrophoretic pattern representing digestion of recombinant pHANNIBAL vector containing sense and antisense fragment with different restriction enzymes.

used to produce double-stranded RNA (dsRNA). At the beginning dsRNA was accomplished by transforming plants with sense and antisense RNA construct separately. And later on, plants were crossed to produce dsRNA. The hpRNAi comprise of an inversely repeated sequence of the target gene (with the spacer 
region between the repeats) and this region is flanked by a promoter and a terminator. A hairpin structure is formed when the RNA is transcribed from such a transgene as a result of self hybridization. Hence a single-stranded loop region is formed which comprise of the spacer region and the stem region encoded by base paired inverted repeats. The siRNA is synthesized from the whole length of the stem but few or none are produced from the loop [24]. In various plants hpRNA construct containing sense and antisense arm ranging from $98-853$ nucleotide gave efficient silencing of the target gene. And it was also found that the presence of an intron increased silencing in ihpRNA constructs to $90 \%$ $100 \%$. Hence, RNAi induced silencing of the gene was much higher than obtained using either co-suppression or anti-sense constructs [25].

It has been demonstrated that almost $100 \%$ of the plants transformed with an intron-containing hairpin construct showed silencing [26]. So, RNAi cassettes are constructed by using an intron spacer. In the present study, the pHANNIBAL RNAi vector was used to directionally clone PCR products from Centella $D X R$ gene to be easily converted into a highly effective hpRNA silencing construct

\subsection{Cloning of Hp RNAi Construct in the pART27 Binary Vector}

The recombinant pHANNIBAL vector, as well as the pART27 binary vector, was digested with NotI restriction enzyme (Figure 5). The digestion of pHANNIBAL vector at NotI site results in the release of $\sim 3.6 \mathrm{~kb}$ RNAi-CaDXR gene cassette. This gene cassette was sub cloned in the NotI site of the binary vector pART27 and successfully transformed in the $\mathrm{DH} 5 \alpha$ strain of the E. coli. The transformed

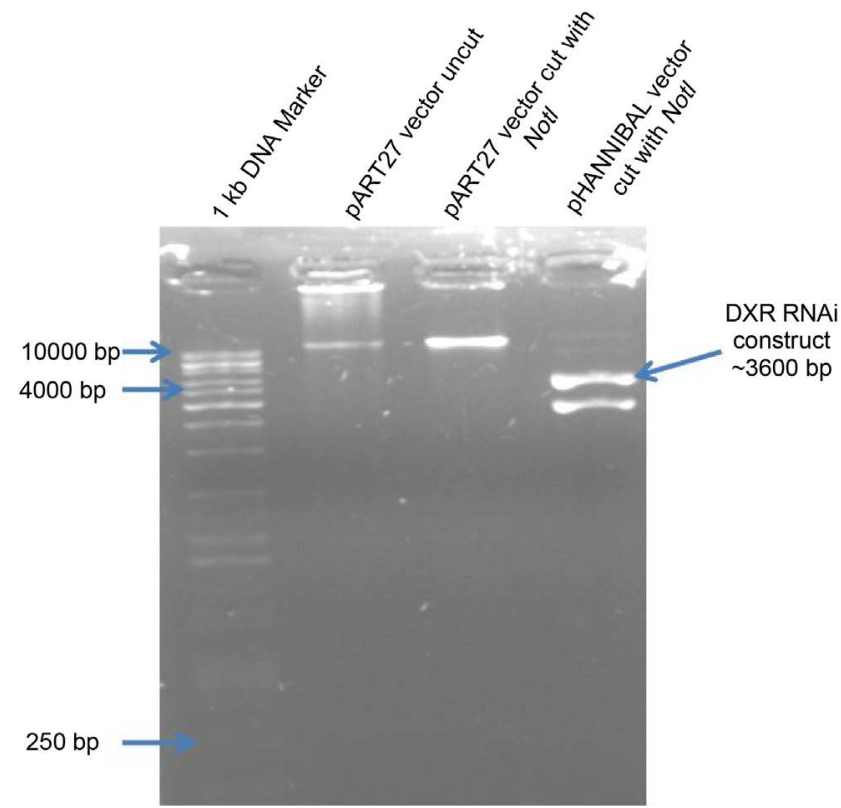

Figure 5. Electrophoretic pattern representing of pART27 binary vector and pHANNIBAL vector with DXR RNAi construct digested with NotI restriction enzyme. 
culture was placed on LB plates containing spectinomycin/IPTG/X-Gal plates for blue-white screening (Figure 6). Recombinant clones were digested with different enzymes to confirm the presence of sense and antisense inserts fragments (273 bp) (Figure 7).

\subsection{Transient Expression Analysis of Ca-DXR RNAi Construct in Nicotiana tabacum and Centella asiatica}

Agrobacterium competent cells are prepared by two methods depending upon the choice of transformation method used i.e. freeze-thaw method and electroporation. Though the freeze-thaw method of transformation is simple and can

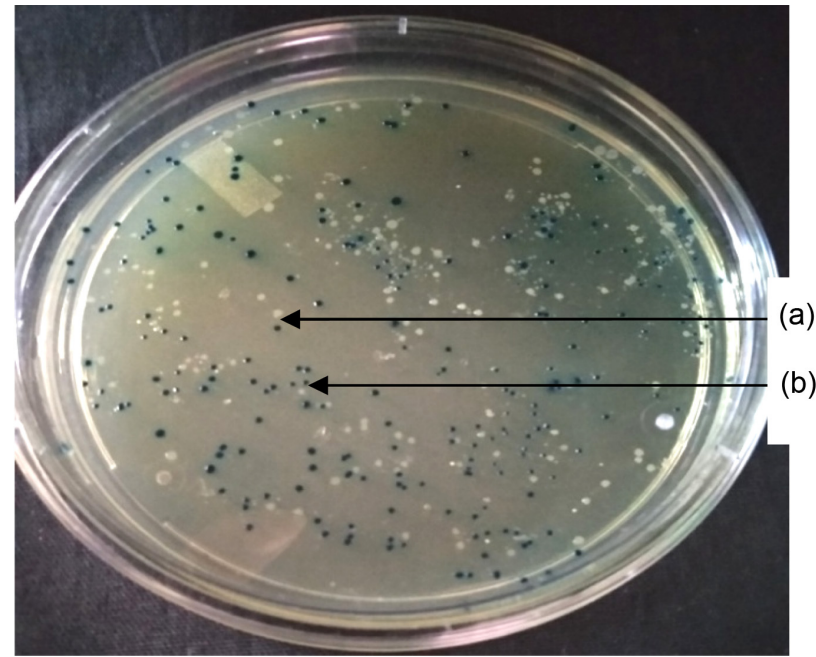

Figure 6. DH5 a E. coli strain transformed with pART27 vector having pHANNIBAL DXR RNAi construct. (a) White colonies represent recombinant; (b) Blue colonies represents non-recombinant.

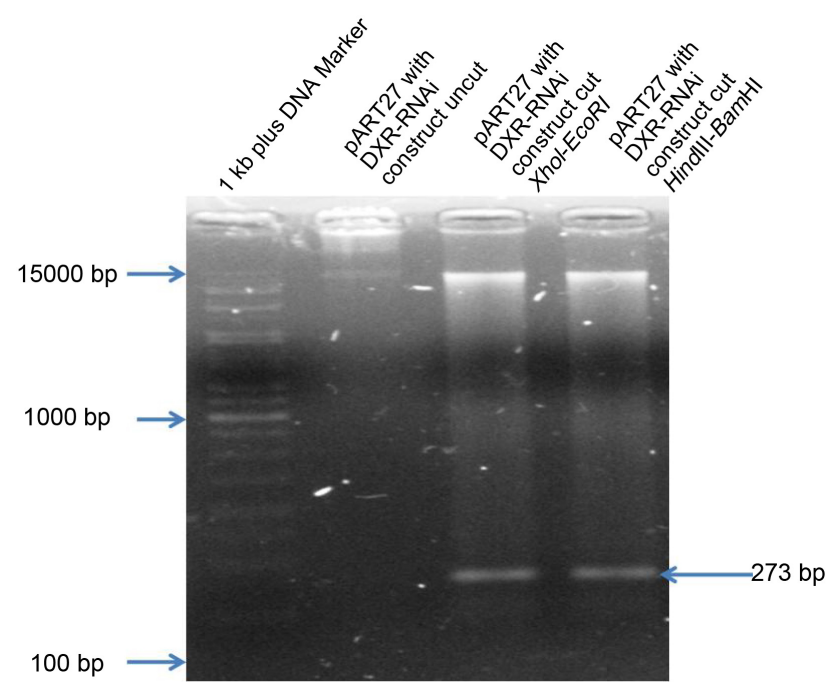

Figure 7. Electrophoretic pattern representing of recombinant pART27 binary vector with DXR RNAi construct digested with different restriction enzymes. 
be easily performed in the lab while electroporation method requires Electroporator (an instrument which uses electrical voltage to introduce pores in the cell membrane) which makes the method expensive but transformation efficiency is more in the electroporation method than in the freeze-thaw method [27]. Thus, in the present study electroporation was used as a method of choice. In the present study, the positive pART27 with RNAi-DXR construct was electroporated into Agrobacterium Agl1 electro-competent cell. The electroporated mixture was spread on LB agar plates having spectinomycin for selection of construct and rifampicin as selection for Agrobacterium. After $48 \mathrm{hrs}$ of incubation under $28^{\circ} \mathrm{C}$, colonies were seen in the transformed plate and no colonies were seen in the control plate.

Transient expression assays provide a rapid and convenient tool for basic research in plant biology. They have been developed for gene function studies [28] [29] and have also proved helpful for assessing the activity of gene constructs before undertaking stable transformation [30]. Agrobacterium-mediated transient expression systems are roughly divided into two methods, namely agroinfiltration using a needleless syringe (syringe infiltration) and vacuum infiltration [31] [32]. In syringe infiltration, an Agrobacterium suspension is infiltrated into the abaxial side of the leaves using a needleless syringe. Using this method, the ability of various constructs can be accessed on the same leaf simultaneously. However, recombinant protein accumulation is markedly influenced by leaf age as well as its position [33]. Agro infiltration has been demonstrated to be effective for transient expression in many plant species including tobacco [34], grapevine [35], lettuce, tomato, Arabidopsis [36], switchgrass [37], radish, pea, lupine, and flax [38]. Therefore, based on these earlier reports in our study also the hpRNAi construct was inoculated in Nicotiana and Centella plant by using syringe Agro infiltration method. The gene construct was first tested in Nicotiana tabacum leaves because it is amenable to genetic transformation, can yield high amounts of biomass rapidly, and is a prolific seed producer for scale-up production [39].

In the present investigation, the gene construct was first tested in Nicotiana tabacum leaves. Careful infiltration was done in the two independent leaves of the same tobacco plant whereas an uninfiltrated tobacco leaf of other plant was taken as positive control. Successful infiltration was observed by wetting area of the leaf.

\subsection{Expression of RNAi Construct Analyzed Using Semi-Quantitative RT-PCR}

Semi-quantitative RT-PCR was used to confirm the suppression of the $D X R$ RNAi gene construct in the tobacco leaf tissues around the infiltration zone. The $D X R$ transcript was significantly reduced compared with the controls (Figure 8(a) and Figure 8(b)). Reduction of the $D X R$ transcript was generally observed 4 days post infiltration (dpi) and persisted until $8 \mathrm{dpi}$. Partial reduction of the $D X R$ transcript was observed after 4 days of infiltration. However, the reduction 
(a)

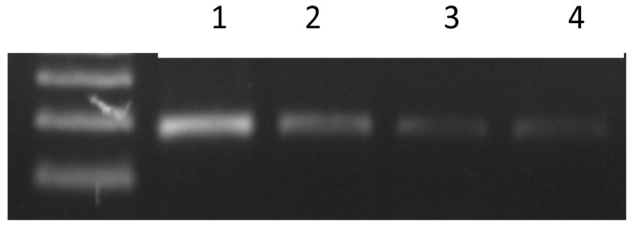

DXR

(b)

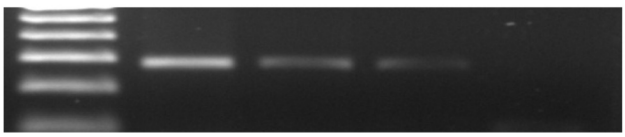

Ubi 10

DXR

Figure 8. Electrophoretic pattern representing Semi-quantitative RT-PCR analysis of transient silencing of DXR gene in two independent Tobacco leaves ((a) and (b)). lane1-Control, lane2-4 days post infiltration, lane3-6 days post infiltration, lane4-8 days post infiltration.

(a)

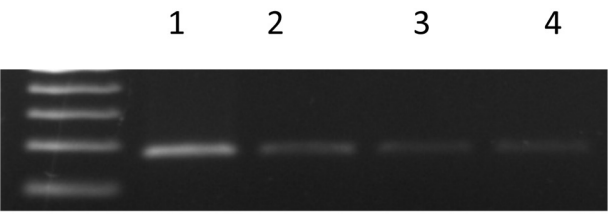

DXR

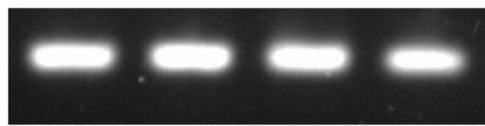

Ubi 10

(b)

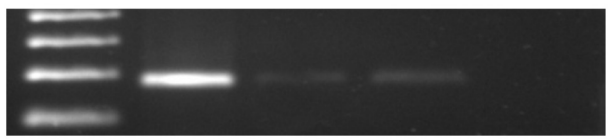

DXR

Figure 9. Electrophoretic pattern representing Semi-quantitative RT-PCR analysis of transient silencing of the DXR gene in two independent Centella leaves ((a) and (b)). lane1-Control, lane2-4 days post infiltration, lane3-6 days post infiltration, lane4-8 days post infiltration.

in the transcript increased as much as $90 \%$ - 99\% after 8 days of infiltration. our results are in accordance with the previous finding in tobacco and potato that the production of siRNAs for the target gene in the infiltrated zones started as early as 4 days post infiltration and reached a peak abundance by day 8 [40] [41].

After confirmation that the Ca-RNAi construct was working in Tobacco plant then we agroinfiltrated two independent leaves of Centella also as way as done in tobacco and RT-PCR was carried out using the $D X R$ specific primers to check the silencing suppression of $D X R$ specific mRNA. RT-PCR results in Centella revealed very less expression of $D X R$ transcript after 4 days and no expression of endogenous $D X R$ in the leaves after 8 days but strong expression of $D X R$ (273 bp) in the control plant was evident (Figure 9(a) and Figure 9(b)). Thus, the RT-PCR result revealed, that introduction of the sRNA specific to $D X R$ gene in Centella asiatica limits the transcript level of endogenous $D X R$ by activating the 
sequence-specific RNA degradation process.

\section{Conclusion}

In the present study, we have successfully designed the DXR RNAi hairpin construct and cloned it into a pART27 binary vector for plant transformation. Henceforth, the transient analysis revealed that the $D X R$ gene is knocked down in agro infiltrated Centella and tobacco plant as evidenced by semi-quantitative RT PCR results. To date, a large number of plant genes encoding $D X R$ have been cloned and characterized. The $D X R$ gene provides the basis for increasing terpenoid production by genetic engineering approach. Therefore, the present study will be helpful to understand the triterpenoid saponins i.e., centelloids biosynthesis in Centella asiatica and the RNAi knockdown approach by targeting the key regulatory gene 1-deoxy-D-xylulose-5-phosphate reductoisomerase $(D X R)$ of the MEP pathway shall serve as a benchmark to elucidate triterpenoid biosynthesis pathway in Centella asiatica.

\section{Conflicts of Interest}

The authors declare that they have no conflict of interest.

\section{Author Contributions}

PS conceptualized the study. Primers were designed by BKB. Molecular works were carried out by RS. RK helped in execution of the experiments. MKM revised the manuscript.

\section{References}

[1] Kalita, R., Modi, M.K. and Sen, P. (2018) RNAi Mediated Silencing of 3-Hydroxy3-Methylglutaryl-CoA Reductases (HMGR) in Centella asiatica. Gene Report, 11, 52-57. https://doi.org/10.1016/j.genrep.2018.02.004

[2] Jamil, S.S., Nizami, Q. and Salam, M. (2007) Centella asiatica (Linn.) Urban: A Review. Natural Product Radiance, 6, 158-170.

[3] Chandrika, U.G. and Kumar, P.A.P. (2015) Gotu Kola (Centella asiatica): Nutritional Properties and Plausible Health Benefits. Advances in Food and Nutrition Research, 76, 1043-4526. https://doi.org/10.1016/bs.afnr.2015.08.001

[4] Chopra, R.N. and Nayar, S.L. and Chopra, I.C. (1986) Glossary of Indian Medicinal Plants (Including the Supplement). Council of Scientific and Industrial Research, New Delhi, 51-83.

[5] Diwan, P.C., Karwande, I. and Singh, A.K. (1991) Anti-Anxiety Profile of Mandukparni Centella asiatica Linn in Animals. Fitoterapia, 62, 255-257.

[6] Schaneberg, B.T., Mikell, J.R., Bedir, E. and Khan, I.A. (2003) An Improved HPLC Method for Quantitive Determination of Six Triterpenes in Centella asiatica Extracts and Commercial Products. Pharmazie, 58, 381-384.

[7] Brinkhaus, B., Lindner, M., Schuppan, D. and Hahn, E.G. (2000) Chemical, Pharmacological and Clinical Profile of the East Asian Medical Plant Centella asiatica. Phytomedicine, 7, 427-428. https://doi.org/10.1016/S0944-7113(00)80065-3

[8] Pandey, N.K., Tewari, K.C., Tewari, R.N., Joshi, G.C., Pande, V.N. and Pandey, G. 
(1993) Medicinal Plants of Kumaon Himalaya. In: Dhar, U., Ed., Strategies for Conservation of Himalaya, Gyanodaya Prakashan, Nainital, 293-302.

[9] Singh, H.G. (1989) Himalayan Herbs and Drugs, Importance and Extinction Threat. Journal of Medicinal Plants Research, 10, 47-52.

[10] Sharma, B.L. and Kumar, A. (1998) Biodiversity of Medicinal Plants of Triyugi Narain (Garhwal Himalaya) and their Conservation. National Conference on Recent Trends in Spices and Medicinal Plant Research, 78, 1-4.

[11] Stermer, B.A., Bianchini, G.B. and Korth, K.L. (1994) Regulation of HMG-COA Reductase Activity in Plants. The Journal of Lipid Research, 35, 1133-1140.

[12] Mocellin, S. and Provenzano, M. (2004) RNA Interference: Learning Gene KnockDown from Cell Physiology. Journal of Translational Medicine, 2, Article No. 39. https://doi.org/10.1186/1479-5876-2-39

[13] Estévez, J.M., Cantero, A., Romero, C., Kawaide, H., Jiménez, L.F., Kuzuyama, T., Seto, H., Kamiya, Y. and León, P. (2000) Analysis of the Expression of CLA $\mathrm{A}_{1}$, a Gene that Encodes the 1-Deoxyxylulose 5-Phosphate Synthase of the 2-Cmethyl-DErythritol-4-Phosphate Pathway in Arabidopsis. Plant Physiology, 124, 95-103. https://doi.org/10.1104/pp.124.1.95

[14] Carretero-Paulet, L., Cairó, A., Botella-Pavía, P., Besumbes, O., Campos, N., Boronat, A. and Rodríguez-Concepción, M. (2006) Enhanced Flux through the Methylerythritol 4-Phosphate Pathway in Arabidopsis Plants Overexpressing Deoxyxylulose 5-Phosphate Reductoisomerase. Plant Molecular Biology, 62, 683-695. https://doi.org/10.1007/s11103-006-9051-9

[15] Yang, Y., Li, R. and Qi, M. (2000) In Vivo Analysis of Plant Promoters and Transcription Factors by Agro Infiltration of Tobacco Leaves. The Plant Journal, 6, 543-551. https://doi.org/10.1046/j.1365-313x.2000.00760.x

[16] Leuzinger, K., Dent, M., Hurtado, J., Stahnke, J., Lai, H., Zhou, X. and Chen, Q. (2013) Efficient Agroinfiltration of Plants for High-Level Transient Expression of Recombinant Proteins. JoVE-Journal of Visualized Experiments, 77, 50521. https://doi.org/10.3791/50521

[17] Loomis, W.D. (1974) Overcoming Problems of Phenolics and Quinines in the Isolation of the Plant Enzymes and Organelles. Methods in Enzymology, 31, 528-544. https://doi.org/10.1016/0076-6879(74)31057-9

[18] Fujii, N., Inui, T., Iwasa, K., Morishige, T. and Sato, F. (2007) Knockdown of Berberine Bridge Enzyme by RNAi Accumulates (S)-Reticuline and Activates a Silent Pathway in Cultured California Poppy Cells. Transgenic Research, 16, 363-375. https://doi.org/10.1007/s11248-006-9040-4

[19] Park, S.U., Yu, M. and Facchini, P.J. (2002). Antisense RNA-Mediated Suppression of Benzophenanthridine Alkaloid Biosynthesis in Transgenic Cell Cultures of California Poppy. Plant Physiology, 128, 696-706. https://doi.org/10.1104/pp.010741

[20] Park, S., Yu, M. and Facchini, P.J. (2003) Modulation of Berberine Bridge Enzyme Levels in Transgenic Root Cultures of California Poppy Alters the Accumulation of Benzophenanthridine Alkaloids. Plant Molecular Biology, 51, 153-164. https://doi.org/10.1023/A:1021199311049

[21] Han, J.Y., Kwon, Y.S. and Yang, D.C. (2006) Expression and RNA Interference-Induced Silencing of the Dammarenediol Synthase Gene in Panax ginseng. Plant Cell Physiology, 47, 1653-1662. https://doi.org/10.1093/pcp/pcl032

[22] Spencer, P.S., Roy, D.N., Ludolph, A., Hugon, J., Dwivedi, M.P. and Schaumburg, H.H. (1986) Lathyrism: Evidence for Role of the Neuroexcitatory Amino Acid BOAA. Lancet, 2, 1066-1067. https://doi.org/10.1016/S0140-6736(86)90468-X 
[23] Williams, M., Clark, G., Sathasivan, K. and Islam, A.S. (2004) RNA Interference and Its Application in Crop Improvement. Plant Tissue Culture and Biotechnology, 14, $1-18$.

[24] Watson, J.M., Fusaro, A.F., Wang, M. and Waterhouse, P.M. (2005) RNA Silencing Platforms in Plants. FEBS Letters, 579, 5982-5987.

https://doi.org/10.1016/j.febslet.2005.08.014

[25] Wesley, S.V., Helliwell, C.A., Smith, N.A., Wang, M.B. and Rouse, D.T. (2001) Construct Design for Efficient, Effective and High-Throughput Gene Silencing in Plants. Plant Journal, 27, 581-590. https://doi.org/10.1046/j.1365-313X.2001.01105.x

[26] Smith, N.A., Singh, S.P., Wang, M.B., Stoutjesdijk, P.A., Green, A.G. and Waterhouse, P.M. (2000) Total Silencing by Intron-Spliced Hairpin RNAs. Nature, 407, 319-320. https://doi.org/10.1038/35030305

[27] Wise, A.A., Liu, Z. and Binns, A.N. (2006) Three Method for the Introduction of Foreign DNA into Agrobacterium. Methods in Molecular Biology, 343, 43-53. https://doi.org/10.1385/1-59745-130-4:43

[28] Hellens, R.P., Allan, A.C., Friel, E.N., Bolitho, K., Grafton, K., Templeton, M.D., Karunairetnam, S., Gleave, A.P. and Laing, W.A. (2005) Transient Expression Vectors for Functional Genomics, Quantification of Promoter Activity and RNA Silencing in Plants. Plant Methods, 1, Article No. 13. https://doi.org/10.1186/1746-4811-1-13

[29] Lee, M.W. and Yang, Y. (2006) Transient Expression Assay by Agroinfiltration of Leaves. In: Salinas, J. and Sanchez-Serrano, J.J., Eds., Arabidopsis Protocols, Humana Press, New York, 225-229. https://doi.org/10.1385/1-59745-003-0:225

[30] Sparkes, I.A., Runions, J., Kearns, A. and Hawes, C. (2006) Rapid, Transient Expression of Frescent Fusion Proteins in Tobacco Plants and Generation of Stably Transformed Plants. Nature Protocols, 1, 2019-2025. https://doi.org/10.1038/nprot.2006.286

[31] Kapila, J., DeRycke, R., VanMontagu, M. and Angenon, G. (1997) An Agrobacterium Mediated Transient Gene Expression System for Intact Leaves. Plant Science, 122, 101-108. https://doi.org/10.1016/S0168-9452(96)04541-4

[32] Vézina, L.P., Faye, L., Lerouge, P.D., Aoust, M.A., Marquet-Blouin, E., Burel, C., Lavoie, P.O., Bardor, M. and Gomord, V. (2009) Transient Co-Expression for Fast and High-Yield Production of Antibodies with Human-Like N-Glycans in Plants. Plant Biotechnology Journal, 7, 442-455. https://doi.org/10.1111/j.1467-7652.2009.00414.x

[33] Piotrzkowski, N., Schillberg, S. and Rasche, S. (2012) Tackling Heterogeneity: A Leaf Disc-Based Assay for the High-Throughput Screening of Transient Gene Expression in Tobacco. PLOS ONE, 7, 45803. https://doi.org/10.1371/journal.pone.0045803

[34] Sheludko, Y.V., Sindarovska, Y.R., Gerasymenko, I.M. and Bannikova, M.A. (2006) Comparison of Several Nicotiana Species as Host for High-Scale AgrobacteriumMediated Transient Expression. Biotechnology and Bioengineering, 96, 608-614. https://doi.org/10.1002/bit.21075

[35] Santos-Rosa, M., Poutaraud, A., Merdinoglu, D. and Mestre, P. (2008) Development of a Transient Expression System in Grapevine via Agro-Infiltration. Plant Cell Reports, 27, 1053-1063. https://doi.org/10.1007/s00299-008-0531-Z

[36] Wroblewski, T., Tomczak, A. and Michelmore, R. (2005) Optimization of Agrobacterium-Mediated Transient Assays of Gene Expression in Lettuce, Tomato and Arabidopsis. Plant Biotechnology Journal, 3, 259-273. 
https://doi.org/10.1111/j.1467-7652.2005.00123.x

[37] VanderGheynst, J.S., Guo, H.Y. and Simmons, C.W. (2008) Response Surface Studies that Elucidate the Role of Infiltration Conditions on Agrobacterium tumefaciens-Mediated Transient Transgene Expression in Harvested Switchgrass (Panicum virgatum). Biomass and Bioenergy, 32, 372-379.

https://doi.org/10.1016/j.biombioe.2007.09.014

[38] Van der Hoorn, R.A.L., Laurent, F., Roth, R. and De Wit, P.J. (2000) Agroinfiltration Is a Versatile Tool That Facilitates Comparative Analysis of Avr9/Cf-9-Induced and Avr4/Cf-4-Induced Necrosis. Molecular Plant-Microbe Interactions, 13, 439-446. https://doi.org/10.1094/MPMI.2000.13.4.439

[39] Lai, H., He, J., Engle, M., Diamond, M.S. and Chen, Q. (2012) Robust Production of Virus-Like Particles and Monoclonal Antibodies with Gemini Viral Replicon Vectors in Lettuce. Plant Biotechnology Journal, 10, 95-104.

https://doi.org/10.1111/j.1467-7652.2011.00649.x

[40] Koscianska, E., Kalantidis, K., Wypijewski, K., Sadowski, J. and Tabler, M. (2005) Analysis of RNA Silencing in Agroinfiltrated Leaves of Nicotiana benthamiana and Nicotiana tabacum. Plant Molecular Biology, 59, 647-661.

https://doi.org/10.1007/s11103-005-0668-x

[41] Bhaskar, P.B., Venkateshwaran, M., Wu, L., Ane, J.M. and Jiang, J. (2009) Agrobacterium-Mediated Transient Gene Expression and Silencing: A Rapid Tool for Functional Gene Assay in Potato. PLoS ONE, 4, e5812.

https://doi.org/10.1371/journal.pone.0005812

\section{Abbreviation}

Ca-DXR: Centella asiatica 1-deoxy-D-xylulose-5-phosphate reductoisomerase NCBI: National Centre for Biotechnology Information

RT-PCR: Real-time Polymerase Chain Reaction

Ca-RNAi: Centella asiatica RNA interference

IUCN: International Union for Conservation of Nature and Natural Resources hpRNA: Hairpin RNA

cDNA: Complementary DNA

MEP pathway: 2-C-methyl-D-erythritol 4-phosphate MEP pathway 